\title{
Obesity Prevalence and Dietary Intake of Antioxidants in Native American Adolescents
}

\author{
Maria C. Perez, Benjamin D. Knisley, Grace E. Crosby, Shasha Zheng, M. Margaret Barth \\ Department of Public Health Sciences, Nutrition \& Food Sciences, California Baptist University, USA
}

\section{Article Info}

Article history:

Received Jun 7, 2016

Revised Aug 10, 2016

Accepted Aug 25, 2016

\section{Keyword:}

Adolescents

Antioxidants

Dietary assessment

Native american

Obesity

\begin{abstract}
Antioxidants are well known for possessing anti-inflammatory properties, which can reduce the risk of chronic disease and obesity. However, very little research has been done to examine antioxidant intake among adolescent minority populations such as Native American adolescents. Our study examined the significance of antioxidant intake among Native American adolescents at an urban residential high school in Southern California. Our study population consisted of 183 male and female Native American adolescents, 14-18 years of age, representing 43 tribes from across the United States. Students' primary source of meals was provided by the school food service. Based on the BMI calculations, the rate of obesity within our population was $38 \%$ for males and $40 \%$ for females, more than two-fold the national rate indicated by NHANESIII data. We used the Harvard School of Public Health Youth/Adolescent Questionnaire (HSPH YAQ), a semiquantitative food frequency questionnaire, to examine antioxidant nutrient intake and evaluate the differences in the intake between normal and obese weight students. Statistical analysis of the results showed that intakes of vitamins $\mathrm{C}, \mathrm{E}$, and lycopene were the antioxidant nutrients found to be significantly different between normal and obese weight students and intakes of these nutrients were found to be higher among normal weight students (pvalues $=0.02451,0.00847$, and 0.04928 , respectively). These results suggest that dietary intake of antioxidants could be increased among Native American adolescents. Further research is needed to confirm our findings and identify effective ways for school food service to incorporate antioxidant rich foods into school menus.
\end{abstract}

Copyright (C) 2016 Institute of Advanced Engineering and Science. All rights reserved.

\section{Corresponding Author:}

M. Margaret Barth, Department of Public Health Sciences,

California Baptist University,

8432 Magnolia Ave, Riverside, CA, 92504, United States of America.

Email: mbarth@calbaptist.edu

\section{INTRODUCTION}

Worldwide, a dramatic increase in adolescent obesity rates has been observed. In the US, the 20092010 National Health and Nutrition Examination Survey (NHANES) show 17.9\% of adolescents classified as obese. Native American adolescents are highly affected by the epidemic of obesity and its comorbidities compared with other ethnic groups in the United States. Today, $40 \%$ to $50 \%$ of Native American children will be classified as either overweight or obese before they are 10 years of age, opposed to data from a century ago showed that Caucasian and Lakota children were equivalent in weight and body mass index [1]. While these results are no longer the case, there have been several efforts made to enforce healthy programs in Native American communities. In a study done in South Dakota investigating overweight and obesity among Native American children ages 5-19 across 13 academic calendar years, the results showed that Native American children consistently had higher rates of overweight or obesity compared to Caucasian 
children [2]. Similarly, the Center for Disease Control and Prevention has also reported that childhood obesity has more than doubled in children and quadrupled in adolescents in the past 30 years [3].

The consequences of adolescent obesity have immediate and long-term effects on the health of Native Americans. In a population-based sample of 5-17 year olds, $70 \%$ of obese youth had at least one risk factor for cardiovascular disease [4]. It has also been demonstrated that sound nutrition plays an important role in prevention of obesity \& chronic diseases, including coronary heart disease, cancer, stroke, and diabetes. For this reason, nutrition was identified as a priority area for Healthy People 2010, and continues to remain an important objective for Healthy People 2020. Based on recent reports of significantly-increased prevalence of obesity among Native American adolescents ( 40\%), there is increased interest for understanding the role of nutrition in prevention of obesity in this population [2].

In the last ten years, US population-based surveys have shown that adolescents fail to meet dietary recommendations for overall nutritional status. Food intakes associated with healthier diets to support nutrition status often include higher intakes of fruit and vegetables, rich in antioxidants. The current daily recommendations for fruit and vegetables in the adolescent diet are two cups of fruit and three cups of vegetables. However, less than 1 in 10 adolescents meet the recommended fruit and vegetable intake according to NHANESIII. Six national surveys show that intakes of fruit and vegetables have continued to decrease over the last twenty years through 2010 among high school age populations. Only 22\% of high school students met the recommendation of eating greater than or equal to five servings of fruit and vegetables [5].

Other recent reports have shown that adolescent ages 12-19 years consumed lower amounts of fruit and vegetables than children 2-19 years of age [5]. Less than 1\% of males 14-18 years of age met the USDA dietary recommendations for fruit and vegetable intake [4]. Overall, US adolescents take in higher proportion of energy from fat and consume fewer vitamins including antioxidants [6]. Thus, the overall objective of this study is to assess nutritional factors, specifically dietary intake of antioxidants associated among normal and obese weight Native American adolescents.

\section{RESEARCH METHOD}

The experimental design for this study is a cross sectional, epidemiologic study at Sherman Indian High School located in Riverside, California. Sherman Indian High School is an off-reservation boarding high school for Native Americans. Originally opened in 1892 as the Perris Indian School, in Perris, California, the school was relocated to Riverside, California in 1903, under the name The Sherman Institute. When the Western Association of Schools and Colleges accredited the school in 1971, it became known as the Sherman Indian High School. The Bureau of Indian Education/Bureau of Indian Affairs and the United States Government Department of the Interior operate it; the school serves grades 9 through 12. The study population consisted of 183 male and female Native American adolescents, 14-18 years of age, representing 43 different tribes from across the United States. The study included obtaining of anthropometric measures to determine obesity prevalence, and dietary intake assessment to determine adequacy of antioxidant nutrient intakes relative to recommended levels, and compare intakes of these nutrients in normal and obese weight Native American adolescents.

Anthropometric measures of height $(\mathrm{m})$, weight $(\mathrm{kg})$, waist circumference $(\mathrm{cm})$ and skinfold (mm) measures including tricep and calf were made using NIH standardized protocols, and body mass index (BMI) values were calculated $(\mathrm{kg} / \mathrm{m} 2)$. Obesity prevalence was identified using the anthropometric assessment data. Obesity rate within the population was calculated using BMI $(\mathrm{kg} / \mathrm{m} 2)$ and compared with NHANESIII data. Dietary intake data was obtained using the Harvard School of Public Health Youth Adolescent Questionnaire (HSPH YAQ), a semi-quantitative food frequency method that estimates macronutrients and micronutrients from foods in the adolescent diet. Preliminary focus groups were conducted to confirm the cultural appropriateness of foods in the questionnaire. Weekly sessions were scheduled at each of the four dormitories over an eight-week period for collection of anthropometric and dietary data. Trained faculty and student intern research teams participated in orientation sessions on cultural aspects of Native American and on best practices for survey implementation and anthropometric measurements.

The completed surveys were prepared for scanning by The Harvard T.H. Chan School of Public Health Nutrition Department. Mean usual intakes of antioxidant nutrients were compared between normal and obese weight Native American adolescents along with assessing achievement of recommended dietary allowance (RDA). Data analyses of the anthropometric and nutrient results were conducted at California Baptist University using $\mathrm{R}$ statistical software [7]. A timeline of the Native American adolescent obesity assesment project is shown in Table 1 and includes Phase 1: anthropometric measurements and Phase 2: dietary analysis. 


\section{RESULTS AND ANALYSIS}

\subsection{Anthropometric Assessment}

The first phase of the project was the anthropometric assessment and results are represented in Table 2, which shows total population weight classification by BMI among Native American adolescents in this study. The weight classifications included categories of normal weight (BMI 18.5-24.9), overweight (BMI 25.0-30.0), and obese (BMI greater than or equal to 30.0). Overall obesity rate among the Native American adolescents in the study was 38.3\%. 35.4\% of the male subjects were classified as obese (35 out of 99 males), while $41.7 \%$ of the females were classified as obese (35 out of 84 females). The overall rate of obesity is double the national rate reported in NHANESIII (18\%) for adolescents [2]. The secondary phase of the project, as shown in Figures 1-3, is the dietary assessment, which analyzes antioxidant nutrient intake. This was conducted to identify antioxidant nutrients at risk among normal and obese weight Native American adolescents using the HSPH YAQ. The nutrient results report based on normal or obese weight classification.

\subsection{Dietary Assessment}

Antioxidant nutrient results are reported by normal or obese weight classification. Figure 1 shows the mean usual vitamin C intake among normal (202.91 mg/day) and obese (144.84 mg/day) weight Native American adolescents. The subjects in our study consumed at least $140 \mathrm{mg}$ per day. Both normal and obese weight Native American adolescents intakes of Vitamin C were greater than the U.S. recommended dietary allowance (RDA) (65-75 mg per day). However, the difference in vitamin C consumption between normal weight and obese weight subjects was significantly different ( $\mathrm{p}$-value $<0.05$ ), with normal weight subjects consuming more than obese subjects. Examples of food sources with the highest intake of Vitamin C consumed by the students within the study were citrus fruits, citrus-based juices, fruit punch and smoothies.

Figure 2 shows the mean usual intake of Vitamin E among normal ( $3.14 \mathrm{mg} /$ day) and obese (2.28 $\mathrm{mg} /$ day) weight Native American adolescents. The U.S. RDA is $15 \mathrm{mg}$ per day of vitamin E [8] while the subjects in our study consumed between 2.25 and $3.1 \mathrm{mg}$ per day. Both the normal weight and obese Native American adolescents in our study consumed significantly less than the U.S. RDA of vitamin E per day. The difference in vitamin E consumption between normal weight and obese subjects was significant ( $\mathrm{p}$-value $<$ 0.01). Some of the sources selected with the highest intake of Vitamin E were peanut butter and jelly, oil and vinegar, candy and nuts, and corn chips.

Figure 3 shows the mean usual intake of lycopene among normal (7.62 mg/day) and obese (5.5 mg/day) weight Native American adolescents. Subjects in our study consumed between 5.5 and 9.5 mg per day of lycopene, which is below the recommended amount. Although there is no dietary reference intake (DRI) for lycopene, recent studies recommend 30-35 mg per day [9]. However, the difference in lycopene consumption between normal weight and obese subjects was significant (p-value $<0.05$ ), with normal weight subjects consuming more than obese subjects. Some of the sources selected with the highest intake of lycopene were tomatoes, pizza and pasta sauces.

There was no significant difference found in the usual intakes of other antioxidants including vitamin A, pro vitamin A, and selenium between normal and obese weight subjects.

\subsection{Statistical Analysis}

Results are expressed as mean \pm SEM. Comparison of nutrient intake between normal and obese groups were performed by two-tailed t-test. Significance testing was set at p-value $<0.05$.

Table 1. Timeline of the obesity assessment project on Native American Adolescents

\begin{tabular}{|c|c|c|c|c|c|}
\hline Preliminary & Phase $1^{*}$ & Phase 2* & Phase 3 & Phase 4 & Phase 5 \\
\hline Focus groups & Anthropometrics & Dietary & Comprehensive & Program & Monitoring \\
\hline Usual Intake & Height, weight, & assessment & program & implementation & Evaluation \\
\hline Dietary Patterns & $\begin{array}{l}\text { and waist } \\
\text { skinfolds }\end{array}$ & $\begin{array}{c}\text { and } \\
\text { eating behaviors }\end{array}$ & development & $\begin{array}{l}\text { Active Living } \\
\text { Healthy Living }\end{array}$ & $\begin{array}{l}\text { Sustainability } \\
\text { reporting }\end{array}$ \\
\hline
\end{tabular}

*phases completed

Table 2. Total population weight classification by BMI among Native American adolescents

\begin{tabular}{ccc}
\hline Weight & $\begin{array}{c}\text { Number of } \\
\text { Students }\end{array}$ & Percentage \\
\hline Ulassification & 4 & $2.2 \%$ \\
Normal & 68 & $37.2 \%$ \\
Overweight & 41 & $22.4 \%$ \\
Obese & 70 & $38.3 \%$ \\
\hline
\end{tabular}

IJPHS Vol. 5, No. 3, September 2016 : $221-227$ 


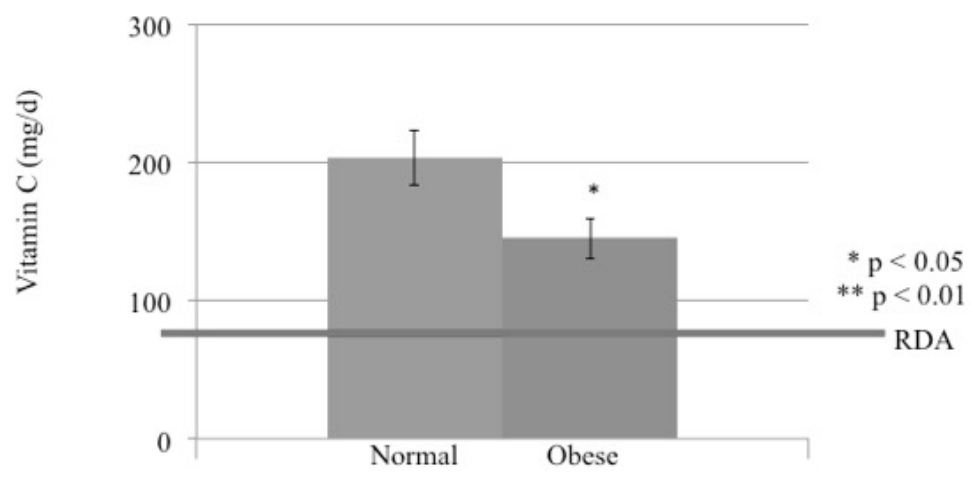

Figure 1. Mean usual intake of vitamin C (mg/day) among normal and obese weight Native American adolescents

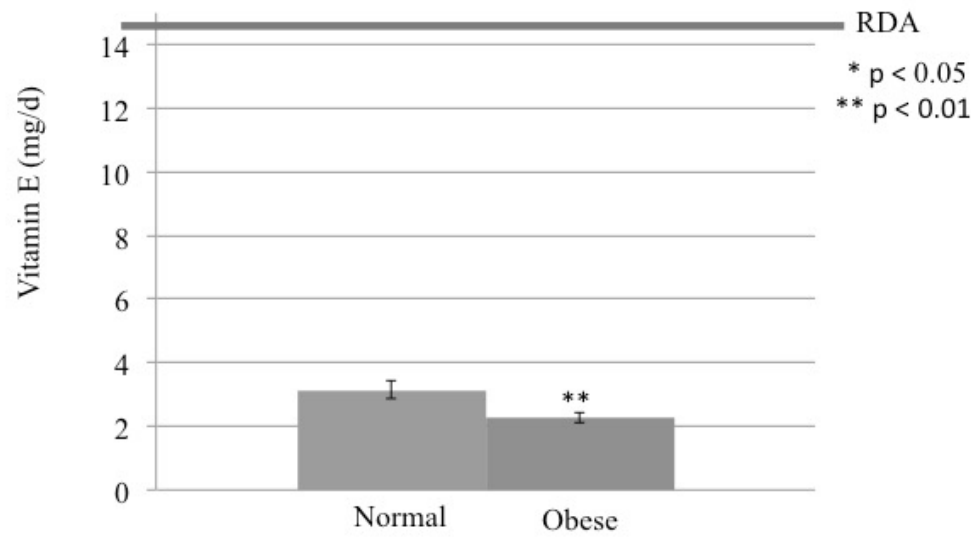

Figure 2. Mean usual intake of vitamin E (mg/day) among normal and obese weight Native American adolescents

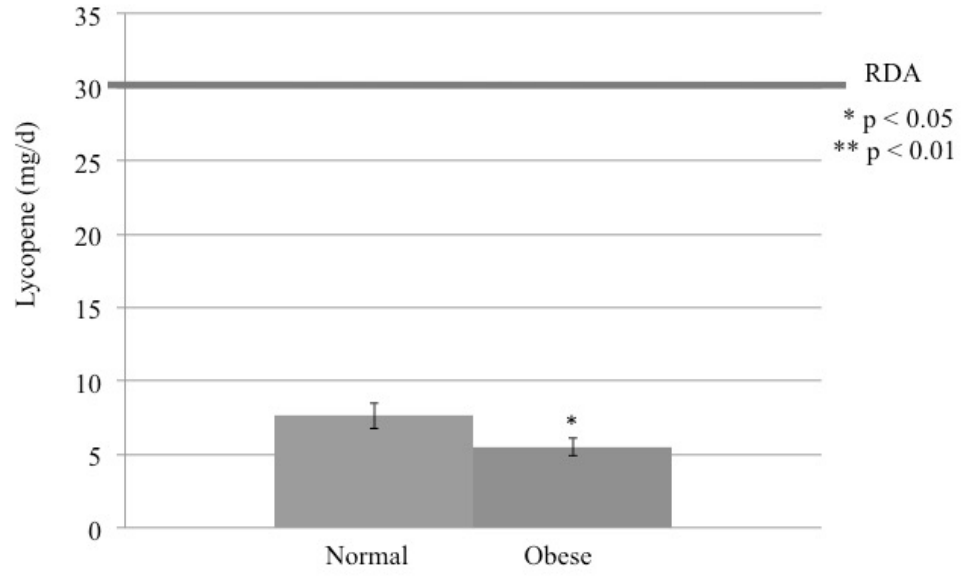

Figure 3. Mean usual intake of lycopene (mg/day) among normal and obese weight Native American adolescents 


\section{CONCLUSION}

In this study, antioxidant nutrient intake was shown to be lower among obese Native American adolescents. Normal and obese weight adolescents did not meet the RDA for vitamin E and lycopene. Vitamin C intake appeared adequate, but it has been reported that obese individuals with evidence of metabolic syndrome may have additional antioxidant needs due to potentially greater oxidative stress. Studies indicate fruit \& vegetable consumption is the most effective way to improve antioxidant intake [10]. Our results suggest that this population could benefit from improved availability of healthy food, including increased fruits and vegetables along with nutrition education on the health benefits of increasing fruit and vegetable intake. An intervention in collaboration with school administration and the foodservice provider would be of benefit in order to increase availability of healthy foods. Further research is needed to confirm the results of this study.

\section{ACKNOWLEDGEMENTS}

We would like to express our thanks to Sherman Indian High School and California Baptist University; for their collaboration and support.

\section{REFERENCES}

[1] D. Styne, "Childhood obesity in American Indians," Journal of Public Health Management and Practice, vol/issue: 16(5), pp. 381-7, 2010.

[2] M. Hearst, K. Biskeborn, M. Christensen, C. Cushing, "Trends of overweight and obesity among white and American Indian school children in South Dakota, 1998-2010,” The Obesity Society, vol/issue: 21(1), pp. E26-32, 2013.

[3] C. Ogden, M. Carroll, B. Kit, K. Flegal, "Prevalence of childhood and adult obesity in the United States 20112012,” Journal of the American Medical Association, vol/issue: 311(8), pp. 806-814, 2014.

[4] D. Freedman, M. Zuguo, S. Srinivasan, G. Berenson, W. Dietz, "Cardiovascular risk factors and excess adiposity among overweight children and adolescents: the Bogalusa Heart Study,” Journal of Pediatrics, vol/issue: 150(1), pp. 12-17, 2007.

[5] E. Holt, L. Steffen, A. Moran, S. Basu, J. Steinberg, J. Ross, C. Hong, A. Sinaiko, "Fruit and vegetable consumption and its relation to markers of inflammation and oxidative stress in adolescents," Journal of the American Dietetic Association, vol/issue: 109(3), pp. 414-21, 2009.

[6] D. Demory-Luce, K. Motil, “Adolescent eating habits," 2016. Available from http://www.uptodate.com/contents/adolescent-eating-habits.

[7] B. Knisley, G. Crosby, L. Carothers, M. Barth, "Health risk of obesity in native American adolescents," International Conference on Public Health Science, vol/issue: 4(2), pp. 94-101, 2015.

[8] R. Beyer, "The role of ascorbate in antioxidant protection of biomembranes: interaction with vitamin $\mathrm{E}$ and coenzyme Q,” Journal of bioenergetics and biomembranes, vol/issue: 26(4), pp. 349-58, 1994.

[9] S. Nielsen, L. Rossen, D. Harris, C. Ogden, "Fruit and vegetable consumtion of U.S. youth," NCHS data brief, no.156, 2014.

[10] P. Guenther, K. Dodd, J. Reedy, S. Krebbs-Smith, "Most americans eat much less than recommended amounts of fruits and vegetables,” Journal of the American Dietetic Association, vol/issue: 106(90), pp. 1371-1379, 2006.

\section{BIOGRAPHIES OF AUTHORS}

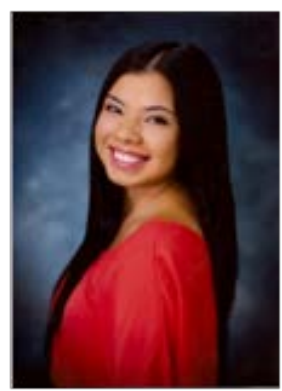

Maria C. Perez is completing her B.S. in Health Science at California Baptist University. She plans to continue her studies and further her education by continuing on to medical school in 2018. 

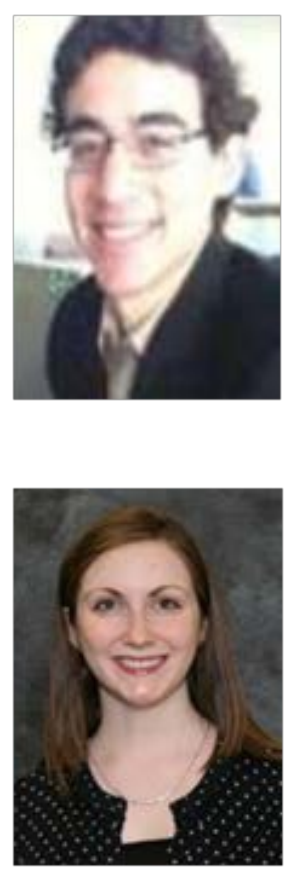

Knisley completed his B.S in Applied Statistical Analysis at California Baptist University in 2015. In 2014, he received the award for excellence in statistics research from the department of natural and mathematical sciences. He is now completing his M.S. in Applied Mathematics at California Baptist University.

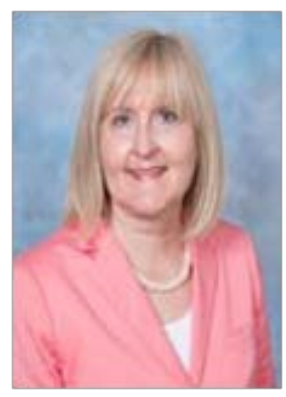

Margaret Barth, PhD, MPH, MBA, is Program Director of Nutrition and Food Sciences and Professor of Nutrition and Food Sciences at California Baptist University. Previously, she was Associate Professor of Nutrition and Food Science at the University of Kentucky, Lexington. Dr. Barth received her PhD in Food Science and Human Nutrition from the University of Illinois.

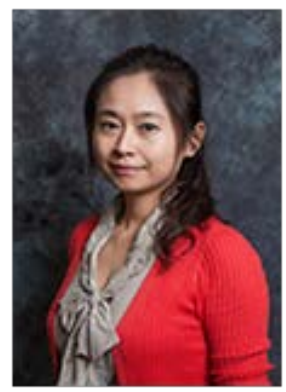

Shasha Zheng, PhD is Assistant Professor of Nutrition and Food Sciences at California Baptist University. Dr. Zheng received her M.A in Medical Nutritional Sciences from Boston University and her $\mathrm{PhD}$ in Human Nutrition from the University of Illinois. 